\title{
Aggressiveness Components and Adaptation to a Host Cultivar in Wheat Leaf Rust
}

\author{
Bénédicte Pariaud, Corinne Robert, Henriette Goyeau, and Christian Lannou
}

First, third, and fourth authors: UMR1290 BIOGER, INRA, F-78850 Thiverval Grignon, France; and second author: UMR EGC, INRA, F-78850 Thiverval Grignon, France.

Accepted for publication 20 March 2009.

\section{ABSTRACT}

Pariaud, B., Robert, C., Goyeau, H., and Lannou, C. 2009. Aggressiveness components and adaptation to a host cultivar in wheat leaf rust. Phytopathology 99:869-878.

Experimental evidence on the capacity of pathogen populations to quantitatively adapt to their hosts and on the life traits that are involved is lacking at this time. In this article, we identified a situation in which a leaf rust pathotype (P1) was found at a high frequency on a widely grown cultivar (Soissons) and we tested the hypothesis that P1 was more aggressive on Soissons than other virulent pathotypes (P2 and P3). Several components of the pathogen life cycle were measured on adult wheat plants in two different experiments under greenhouse conditions: latent period, spore production per lesion and per unit of sporulating tissue, uredinium size, and lesion life span. Regardless of the component, pathotype P1 was repeatedly found to be more aggressive than at least one of the other two pathotypes, with differences of 5 to $51 \%$. Breaking down spore production per lesion into uredinium size and spore production per square millimeter of sporulating tissue showed that the three pathotypes presented different aggressiveness profiles, suggesting different development constraints for the pathogen, either for its growth capacity into host tissues or its ability to exploit the host resources for spore production. Although leaf rust pathotypes present a clonal structure, quantitative differences were found for aggressiveness traits within a pathotype.

Additional keywords: pathogen adaptation, Puccinia triticina.
Plant pathologists have so far predominantly focused their attention on qualitative host-pathogen interactions, based on compatibility relationships and supported by the gene-for-gene model. Interactions between major resistance genes and avirulence genes have shaped pathogen population structure $(47,56)$ in cropping systems as a consequence of cultivar deployment (22) or of the selection process itself that often favored qualitative versus quantitative resistance (5). In comparison, quantitative interactions and their consequences at the population scale have been much less documented. Better knowledge of quantitative hostpathogen interactions is crucial for the development and use of quantitative resistance, which is considered to be one of the most promising ways to increase the sustainability of crop resistance to pathogens. We still lack clear experimental evidence of the capacity of pathogen populations to quantitatively adapt to their hosts as well as information on the life traits that are involved. It is important to better understand the potential impact of such an adaptation on the structure of pathogen populations and on host resistance durability.

In agricultural crops, pathogens are confronted with large, genetically uniform host populations. In such an environment, the fraction of the pathogen population that moves from one selective environment to another (one cultivar to another) is smaller than in wild systems (8). Therefore, it is likely that the host cultivars exert selection pressure for quantitative traits linked to pathogen fitness, as they do for qualitative virulence factors.

It is known that two isolates of a pathogen may differ in aggressiveness. Numerous examples can be found in the literature; for instance, in studies undertaken to evaluate quantitative resistance in host plants. Most of these studies, however, only consider a few

Corresponding author: B. Pariaud; E-mail address: Benedicte.Pariaud@ vilmorin.com

doi:10.1094/PHYTO-99-7-0869

(c) 2009 The American Phytopathological Society isolates and do not allow the inference of conclusions at the population level. In contrast, relatively few studies have examined the quantitative aspects of host-pathogen interactions and their possible consequences at the scale of pathogen populations (43). One of the most well-documented examples is that of a Phytophthora infestans population shift in the Columbia Basin of Washington and Oregon in the United States (36). In a detailed study of several aggressiveness components, Miller et al. (37) found that "new" isolates had higher lesion expansion rates, higher sporulation capacities, and shorter latent periods compared with "old" isolates. They concluded that these differences in aggressiveness at least partially explained the shift in the $P$. infestans population. Their conclusions were supported by other studies $(26,30)$. Similar population shifts also occurred in Europe with the same pathogen (18), and aggressiveness-related traits were involved once again $(16,51)$.

However, selection for quantitative traits may take place at smaller scales, with consequences that are probably more difficult to observe. Several studies have shown that adaptation of plant pathogens for quantitative traits can occur after repeated cycling on the same host $(10,13,29,32,33)$. One of the first studies of pathogen adaptation for quantitative traits based on artificial selection was published by Leonard (34). He maintained a genetically heterogeneous population of Puccinia graminis $\mathrm{f}$. sp. avenae on two different host genotypes for seven asexual generations and showed that the mean infection efficiency (IE) of the population increased by $\approx 10$ to $15 \%$ on the host on which it had been grown but not on the other host. In an artificial selection experiment performed under field conditions, Villaréal and Lannou (55) demonstrated that selection for quantitative traits takes place in the pathogen population at the scale of a single epidemic and results in a higher aggressiveness level at the end of the crop season on the host genotype on which the pathogen population multiplies, confirming earlier results (11). Thus, experimental selection shows a potential for quantitative adaptation of fungal 
pathogens to their host plants. Nevertheless, such approaches may exaggerate the phenomenon that occurs in natural epidemics because a strong selection is artificially applied at each pathogen generation.

Another approach to study how pathogens adapt to their host for quantitative traits is to evaluate the pathogen aggressiveness on its host of origin (usually the cultivar from which it was sampled in the field). Bonman et al. (6) observed that Korean isolates of Magnaporthe grisea induced more disease on Japonica rice cultivars (predominant in Korea) than Philippine isolates and concluded that the pathogen was specifically adapted to the host's genetic background. Andrivon et al. (3) obtained similar results in Phytophthora infestans, comparing French and Moroccan populations on the potato cvs. Bintje (prevalent in France but not grown in Morocco) and Désirée (popular in Morocco but cultivated to a very small extent in France). French and Moroccan populations generally had greater lesion sizes and sporulation capacities on detached leaflets of their host of origin. There is also evidence of a greater aggressiveness of Mycosphaerella graminicola isolates on their wheat cultivar of origin $(1,2)$. Other studies, however, do not show such an adaptation $(23,28,57)$.

Our main goal in this study was to evaluate whether Puccinia triticina (causing leaf rust on wheat) exhibits variability for a set of quantitative traits related to pathogen aggressiveness at the scale of a large population. The first difficulty in such a study is to identify a situation in which clear differences in quantitative traits can be observed and related to the population structure. Although aggressiveness traits are often considered variable in field populations, this is not easy to show experimentally. Knott and Mundt (28) sampled populations of $P$. triticina in field plots and tested their aggressiveness on seedlings of the same cultivars but found no evidence of increased IE or shortened latent period on the cultivar of origin. Thus, we based our study on a specific situation observed in the French leaf rust population. As described by Goyeau et al. (20), this population is structured into a large number of pathotypes with no geographical differentiation within the country, indicating long-distance dispersal and a probable absence of local adaptation to climatic conditions. Moreover, this population presents a clonal structure with a strong correspondence between pathotypes and microsatellite profiles (19). The pathotype distribution is highly dependent on the cultivar grown and results from specific gene-for-gene interactions. In this context, an interesting situation was observed on cv. Soissons, which became very popular in the 1990s. This cultivar represented 10 to $40 \%$ of the French wheat acreage between 1991 and 2002 and was potentially infected by more than 40 pathotypes. Nevertheless, a single pathotype (code 073100 , referred to as P1 in our study) largely dominated the leaf rust population on Soissons, with a frequency usually $>50 \%$ (Table 1 ).

The objectives of our study were to (i) show that differences in aggressiveness occur in $P$. triticina field populations and may account for the dominance of a pathotype, (ii) evaluate how the variability in aggressiveness is distributed within and among pathotypes, and (iii) identify the quantitative traits (aggressiveness components) that are involved.

\section{MATERIALS AND METHODS}

Overview. The aggressiveness levels of three $P$. triticina pathotypes on wheat cv. Soissons were measured on adult wheat plants in the greenhouse. The experiment was done twice. Experiment 1, conducted in spring 2005, was designed to test our hypothesis at the population level, with 17 isolates to represent pathotypes P1 and 014103 (P2) and six isolates to represent pathotype 166336 (P3). Experiment 2, performed in autumn 2005, was designed to confirm the results, with eight isolates per pathotype. For practical reasons, experiment 1 was divided into two trials conducted simultaneously. In the first one (trial 1.1), we measured latent periods and, in the second one (trial 1.2), sporulation, uredinium size, and lesion life span. IE was assessed in both trials.

Plant material. All measurements were performed on wheat adult plants with, as much as possible, homogeneous growth stages and physiological states. Plants of cv. Soissons (with resistance gene $\operatorname{Lrl4a}$ ) were sown in Jiffy pots with two seeds per pot and vernalized for 7 weeks at $8^{\circ} \mathrm{C}$ in a growth chamber. In experiment 1 only, seedlings were sprayed with Spiroxamine (Aquarelle at $2 \mathrm{ml} /$ liter) (Bayer CropScience) 3 weeks after sowing to control powdery mildew. After vernalization, plants were transferred to a greenhouse and left for $\approx 10$ days to acclimatize. The most vigorous seedlings were then individually transplanted into pots (height: $25 \mathrm{~cm}$; diameter: $6.5 \mathrm{~cm}$ ) made from sanitary PVC tubes. Using these cylindrical and narrow pots instead of standard material made it possible to increase the number of replicates. The pots were filled with 0.7 liter of commercial compost (Klasmann Substrat 4, Klasmann France SARL) to which 2.6 and $3.0 \mathrm{~g}$ of slow-release fertilizer (Osmocote 10-1118 , N-P-K) were added in experiments 1 and 2 , respectively. Moreover, each plant received nutritive solution (Hydrokani C2 at a 1:1,000 dilution rate) (Hydro Agri Spécialités, France) during the experiments: 0.5 to $1 \mathrm{ml}$ every week from the fourth week after transplantation in experiment 2 (total of $5 \mathrm{ml} /$ plant) and $2 \mathrm{ml}$ distributed in two applications in experiment 1. During plant growth, natural light was supplemented as needed in both experiments with 400-W sodium vapor lamps between 6:00 a.m. and 9:00 p.m.

In both experiments, we attempted to reduce the variability due to uncontrolled factors. During plant growth, tillers were progressively eliminated to keep only the main stem in each pot except in trial 1.1, in which one to three tillers were kept per pot to increase the number of replicates. Plants with necrotic symptoms at the stem basis (caused by Fusarium spp.), with apparent physiological disorders (localized grayish marks), or with ex-

TABLE 1. Percentages of Puccinia triticina isolates of pathotypes $\mathrm{P} 1, \mathrm{P} 2$, and $\mathrm{P} 3$ in the French population ${ }^{\mathrm{y}}$

\begin{tabular}{|c|c|c|c|c|c|c|c|c|}
\hline \multirow[b]{2}{*}{ Cultivars $^{\mathrm{z}}$} & \multicolumn{8}{|c|}{ Year } \\
\hline & 1999 & 2000 & 2001 & 2002 & 2003 & 2004 & 2005 & 2006 \\
\hline \multicolumn{9}{|l|}{ Wheat } \\
\hline $073100(\mathrm{P} 1)$ & 31 & 57 & 67 & 58 & 48 & 29 & 35 & 38 \\
\hline $166336(\mathrm{P} 3)$ & 0 & 0 & 1 & 2 & 0 & 0 & 0 & 0 \\
\hline Total & 101 & 108 & 124 & 99 & 88 & 61 & 71 & 52 \\
\hline \multicolumn{9}{|l|}{ Other } \\
\hline $166336(\mathrm{P} 3)$ & 0 & 0 & 9 & 11 & 1 & 0 & 0 & 0 \\
\hline Total & 67 & 80 & 110 & 132 & 158 & 138 & 239 & 259 \\
\hline
\end{tabular}

${ }^{y}$ Data are from Goyeau et al. (19) and H. Goyeau (unpublished).

${ }^{\mathrm{z}}$ Isolates were collected at different locations in France. Wheat $=$ cvs. Soissons + Isengrain, Other $=$ main bread wheat cultivars in the French wheat cropping area without Soissons and Isengrain, and Total = total number of isolates collected. 
treme heights or growth stages were discarded. Although $\approx 30 \%$ more plants were grown than were actually needed for inoculation, we had to keep a few plants with apparent minor disorders, which were evenly distributed in the different treatments.

In experiment 1, greenhouse temperature was set at 20 and $15^{\circ} \mathrm{C}$ (day and night, respectively) during plant growth. A fungicide (Spiroxamine) and an insecticide (Deltamethrine, Decis-ce $2 \mathrm{ml} /$ liter) (Bayer CropScience) were applied once to control powdery mildew and aphids, respectively. After 6 weeks, plants used for latent period measurements (trial 1.1) were transferred to a different greenhouse, with an average day and night temperature of 16 and $11^{\circ} \mathrm{C}$, respectively, before inoculation. Plants received a final fungicide treatment (Ethyrimol at $2 \mathrm{ml} / \mathrm{liter}$ ) (Syngenta) 8 and 20 days before inoculation for trial 1.1 and trial 1.2, respectively. This fungicide specifically controls powdery mildew and has no effect on rusts. Plants were grown for 51 and 55 days in the greenhouse before inoculation for trial 1.1 and trial 1.2, respectively.

In experiment 2 , the average day and night temperature was set at 20 and $15^{\circ} \mathrm{C}$, respectively, during plant growth and was reduced to a constant temperature of $15^{\circ} \mathrm{C} 3$ weeks before inoculation to slow down plant growth. After transplantation, plants were sprayed three times (at 2-week intervals) with Spiroxamine and every 2 weeks for aphids (Deltamethrine) until 1 week before inoculation. Plants were grown for 8 weeks in the greenhouse before inoculation.

Fungal material. Single-pustule isolates of the three pathotypes (P1, P2, and P3) were chosen from our laboratory collection. We define pathotypes as pathogen phenotypes resulting from qualitative virulence-resistance reactions. These isolates (Table 2) were collected from unsprayed plots at different locations in France and during different years between 1997 and 2002 (French wheat leaf rust national survey) (20). All P1 and P2 isolates were originally sampled from cv. Soissons. P1 has been the most frequent pathotype on Soissons since 1999 and P2 was the second most frequent pathotype on that cultivar from 1999 to 2001 (Table 1) (20). Although P3 produces a compatible reaction on Soissons, it was almost never found on that cultivar in the survey. Therefore, all P3 isolates in our study originated from cv. Trémie. After they were collected, the isolates were increased up to three times on susceptible wheat cv. Michigan Amber. All isolates were kept at $-80^{\circ} \mathrm{C}$ for long-time conservation; however, for a better standardization of the fungal material, adult plant inoculations were performed with freshly produced spores. Therefore, before inoculation, spores of each isolate were increased for a single multiplication cycle on two to three pots of 7-day-old seedlings of susceptible wheat cv. Michigan Amber, which has never been cultivated in France. The seedlings had been treated with $20 \mathrm{ml}$ of a maleic hydrazide solution $(0.25 \mathrm{~g} /$ liter $)$ to prevent the emergence of secondary leaves and to increase spore production. Before the onset of sporulation, cellophane bags were placed on the pots to prevent cross-contamination. In experiment 1 , we collected the spores produced 11 to 13 days after inoculation. In experiment 2 , spores were collected 11 days after inoculation. The spores were stored for 1 to 5 days in a cabinet $\left(9^{\circ} \mathrm{C}, 35 \%\right.$ relative humidity) and then used to inoculate the adult plants.

In experiment 1 , pathotypes $\mathrm{P} 1$ and $\mathrm{P} 2$ were each represented by 17 isolates and pathotype P3 by 6 isolates (Table 2). Our objective was then to maximize the number of isolates for at least two pathotypes, taking experimental space constraints into account. In experiment 2 , we reduced the number of isolates to eight (randomly chosen) per pathotype for P1 and P2, and we added two new isolates (collected in 2002) for pathotype P3.

Inoculation of adult plants. At inoculation, plant growth stages ranged between boot stage and flowering: 20 and $75 \%$ of the plants were at the flowering stage for experiments 1 and 2, respectively. Growth stages were recorded for each plant before inoculation and evenly distributed among pathotypes and isolates. In experiment 1, plants were inoculated on 14 April (122 days after sowing) and 18 April (126 days after sowing) for trials 1.1 and 1.2 , respectively. In experiment 2, plants were split into two groups for practical reasons and inoculated on 27 or 28 October (124 days after sowing). We inoculated flag leaves of main stems only, except in trial 1.1. In this trial, in order to increase the number of replicates, we kept one pot with three stems, one with two stems, and two with the main stem only for each isolate, which resulted in seven leaves inoculated per isolate. Eight and nine leaves were inoculated with each isolate in trial 1.2 and experiment 2, respectively. Inoculations were performed by applying a 1:10 mixture of leaf rust uredospores and Lycopodium spores on the leaf surface with a soft brush. The leaf surface was inoculated along $5 \mathrm{~cm}$ (trial 1.1, latency measurement), $10 \mathrm{~cm}$ (trial 1.2), or $8 \mathrm{~cm}$ (experiment 2), starting at $5 \mathrm{~cm}$ from the stem in experiment 1 and $7 \mathrm{~cm}$ in experiment 2 . The noninoculated leaf surface was protected with a stencil. Immediately after inoculation, plants were placed in a dew chamber $\left(15^{\circ} \mathrm{C}\right)$ for $24 \mathrm{~h}$ and then returned to the greenhouse until the end of the experiment, with an average day and night temperature set at 22 and $15^{\circ} \mathrm{C}$, respectively.

Measurement of aggressiveness components. IE was estimated on each inoculated leaf from the lesion density on the inoculated surface or, in the case of trial 1.1, on the leaf section used for latency measurements (see below). In this article, the term "lesion" only refers to sporulating lesions and "uredinium" refers to the sporulating tissue within a lesion.

The latent period was measured in trial 1.1 as the time between infection and production of secondary inoculum, and was expressed in degree-days. In leaf rust, sporulation starts when uredinia rupture the leaf epidermis. However, all the lesions present on the same leaf do not start sporulating simultaneously (50). To take this variability into account, sporulating lesions were counted daily on a limited section of $0.5 \mathrm{~cm}^{2}$ until their number stabilized, and the latent period was measured as the time by which half of the maximum number of lesions were sporulating

TABLE 2. Description of Puccinia triticina pathotypes and isolates used in experiments 1 and 2

\begin{tabular}{|c|c|c|c|c|c|c|c|c|c|}
\hline \multicolumn{2}{|r|}{ Pathotypes } & \multirow[b]{2}{*}{$\operatorname{Exp}^{y}$} & \multicolumn{6}{|c|}{ Year of sampling ${ }^{\mathrm{v}}$} & \multirow[b]{2}{*}{ Total $^{\mathrm{z}}$} \\
\hline Code $^{\mathrm{w}}$ & 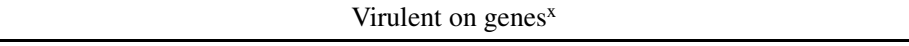 & & 1997 & 1998 & 1999 & 2000 & 2001 & 2002 & \\
\hline $073100(\mathrm{P} 1)$ & Lr2c, Lr3, Lr3bg, Lr3ka, Lr10, Lr14a & 1 & - & - & 3 & 5 & 5 & 4 & 17 \\
\hline $014103(\mathrm{P} 2)$ & $\operatorname{Lr} 2 c, \operatorname{Lr} 13, \operatorname{Lr} 14 a, \operatorname{Lr} 26, \operatorname{Lr} 17 b$ & 1 & 3 & 1 & 4 & 4 & 3 & 2 & 17 \\
\hline & & 2 & 2 & - & 2 & 3 & - & 1 & 8 \\
\hline $166336(\mathrm{P} 3)$ & Lr1, Lr3, Lr3bg, Lr10, Lr13, Lr14a, Lr15, Lr17, Lr17b, Lr20, Lr37, Lr27+Lr31 & 1 & - & - & - & - & 6 & - & 6 \\
\hline
\end{tabular}

${ }^{v}$ Number of isolates per year of sampling.

${ }^{\text {w }}$ Six-digit code based on an 18- $L r$ gene differential set (19).

${ }^{x}$ Wheat resistance genes for which the pathotypes are virulent at the seedling stage (19).

y Two experiments were conducted: experiment 1 in spring 2005 and experiment 2 in autumn 2005.

${ }^{\mathrm{z}}$ Total number of isolates. 
(T50). This time was estimated by linear interpolation around the $50 \%$ count (28). The latent period of each isolate was estimated by the mean value of seven replicates.

Among the leaves inoculated with each isolate, the two or three leaves with the least homogeneous lesion distribution on the leaf surface were discarded and sporulation and uredinium size measurements were performed on six replicates (trial 1.2 and experiment 2). Just before sporulation onset, leaves were placed into bent transparent plastic sheets, forming open tubes of $\approx 10 \mathrm{~cm}$ in diameter, and maintained horizontally with a wooden frame. At each spore collection date, leaves were gently brushed so that the spores fell into the tubes. Spores were then transferred into hermetically closed Eppendorf tubes and weighed. Digital pictures of the leaves were then taken with a scanner (400 ppi) before putting them back in the tubes until the next spore collection date. These pictures were used to determine the total numbers of lesions and the sporulating surface areas by image analysis (Optimas 5; Media Cybernetics, Silver Spring, MD, U.S.A.).

Spores were collected 15 to 23 days after inoculation (dai) in experiment 1 and 13 to 20 dai in experiment 2. Sporulating area was estimated as the average sporulating area between the two collection dates in experiment 1 and was measured at the second collection date only in experiment 2 . Uredinium size (LS, square millimeters) was calculated as the sporulating area divided by the total number of lesions. Spore production per lesion (SpLes, micrograms of spores) was calculated as the amount of spores produced between the collection dates divided by the number of lesions; spore production per unit of sporulating tissue (Spm, micrograms of spores per square millimeter) was calculated as the amount of spores produced between the collection dates divided by the sporulating area. The spores were weighted and not counted. The spore production was then expressed in mass unit but the spore mass and number can be easily related (46). We did not check, however, that each isolate produced spores of identical mass.

In addition, we measured the total spore production per lesion (TotSpLes, in micrograms of spores) from sporulation onset to 59 dai (experiment 1) or 27 dai (experiment 2) and early spore production per lesion at 10 to 13 dai (Early SpLes, in micrograms of spores, experiment 2 only). In experiment 2, TotSpLes was measured over a shorter period of time than in experiment 1 for practical reasons and underestimated the total spore production by the lesions.

For a biotrophic parasite such as $P$. triticina, local tissue exhaustion and death means the end of spore production. Lesion life span was measured by local host tissue necrosis at an advanced stage of the cycle. It was visually estimated for each leaf at 32 and 42 dai in experiments 1 and 2, respectively. The percentage of necrotic host tissue in the inoculated surface was scored according to a six-class scale: $0,<5,5$ to 20,20 to 50,50 to 80 , and $>80 \%$. The sporulation had ceased in the necrotic area whereas it continued in the remaining inoculated leaf surface.

Statistical analyses. All statistical analyses were performed with the SAS software (SAS Institute, Inc., Cary, NC) and were based on linear mixed models ("Proc mixed"), except for lesion life span, which was analyzed with $\chi^{2}$ tests.

Quantitative measurements are made difficult by host and environment variability. Therefore, we defined a series of variables to take this variability into account as much as possible. For trial 1.2 (experiment 1) and experiment 2, plants were randomly distributed into three different greenhouse compartments for practical reasons. The effect of the greenhouse compartment was included in the models as a random effect. In this study, we consider the effects related to the host physiological state as environmental variables for the pathogen. Plant growth stages at inoculation were recorded according to three categories ("boot", "heading", and "flowering"). As an indication of plant nitrogen content, flag leaf color was visually recorded in experiment 1 as "normal" or "light chlorosis". In experiment 2, no variation in leaf color was observed. Localized grayish marks sometimes appeared at the leaf tip and were interpreted as resulting from physiological stress to the plant. They were recorded as "present" or "absent". Flag leaf height (measured from the soil surface to the flag leaf collar) was recorded and included as a co-variable in the models for experiment 2 to account for a potential effect of the proximity to the lamps because they were often turned on during the autumnal period. In trial 1.1, the stem effect (main stem, tiller one, or tiller two) was never found to be significant and was therefore removed from the models. Similarly, the presence of symptoms attributed to Fusarium spp. at the stem basis was never found to be significant and was excluded from the models.

In a first step, IE was estimated by lesion density and analyzed as a function of the pathotype, isolate, and environmental variables. In a second step, latent period, sporulation, and uredinium size were analyzed according to the same variables and with lesion density as an additional co-variable, because it has been shown that lesion density affects these aggressiveness components $(35,46)$. For the latent period, we used a local measurement of lesion density on the leaf section $\left(0.5 \mathrm{~cm}^{2}\right)$ on which that component was measured. When used as a co-variable, lesion density was log-transformed when needed to linearize the data. IE, TotSpLes, and LS were also log-transformed when necessary to improve the residual distribution.

The isolate effect was nested into the pathotype effect and was considered as a random effect. The pathotype effect and environmental effects (except for greenhouse compartments) were considered as fixed effects. Fixed effects were evaluated with type III sum of squares and significance set at $5 \%$. Within each experiment, the same models were used for all aggressiveness components. Interactions between environmental effects or lesion density and the pathotype effect were tested and never found to be significant. Therefore, they were excluded from the analyses presented in the Results section. Multiple comparisons were performed with Tukey-Kramer tests $(\alpha=5 \%)$.

\section{RESULTS}

The first step was to check how the environmental and densitydependence effects potentially influence the aggressiveness measurements and pathotype comparison. We found that there was no interaction between the isolate or the pathotype effect on one side and environmental and density effects on the other side; therefore, we were able to directly compare the different pathotypes for each aggressiveness trait.

Within-pathotype variability. Within pathotypes, the isolate factor had a significant effect on IE in the three datasets (Tables 3 and 4). It also significantly affected the latent period in experiment 1 (Table 3) but not EarlySpLes in experiment 2 (Table 4). In both experiments, differences among isolates of the same pathotype were not detected for $\mathrm{Spm}$. The isolate effect was not consistent across both experiments for SpLes and LS. It was statistically significant for LS (Table 3) but not for SpLes and TotSpLes in experiment 1, whereas the opposite situation was observed in experiment 2 .

Pathotype comparison. The differences among pathotypes for the aggressiveness components measured are summarized in Table 5. The pathotypes did not show any significant difference in IE in experiment 1 in either trial 1.1 or trial 1.2 (Table 3 ). In this experiment, the average IE was 16 lesions $/ \mathrm{cm}^{2}$. In contrast, experiment 2 revealed a significant difference among pathotypes (Table 4).

The pathotype effect was significant for the latent period (Table 3), which was 5\% longer for P3 compared with P1 and P2 (Fig. $1)$. The average difference was of 8 degree-days, which is equivalent to half a day at $16^{\circ} \mathrm{C}$. 
Significant differences among pathotypes were found in both experiments for every sporulation components and for uredinium size (Tables 3 and 4; Fig. 2). In experiment 1, at 15 to 23 dai, SpLes was 18 and $35 \%$ higher for $\mathrm{P} 1$ relative to $\mathrm{P} 2$ and $\mathrm{P} 3$, respectively. The TotSpLes was 17 and $54 \%$ greater for P1 compared with P2 and P3, respectively, and all three pathotypes were significantly different. In experiment 2, TotSpLes was 79 and $98 \%$ higher for $\mathrm{P} 1$ than $\mathrm{P} 2$ and $\mathrm{P} 3$, respectively.

In experiment 1 , the uredinium size of pathotypes $\mathrm{P} 1$ and $\mathrm{P} 2$ was not different, whereas it was $21 \%$ smaller for P3. Pathotypes P1 and P3 produced a similar amount of spores per unit area of sporulating tissue, whereas $\mathrm{Spm}$ was reduced by $16 \%$ in $\mathrm{P} 2$ relative to $\mathrm{P} 1$. These results were confirmed in experiment 2: P3 developed smaller uredinia than P1 and P2 (51\% smaller than P1) and Spm was significantly lower in P2 relative to P1 and P3 (24\% lower than for P1).

At the end of the sporulation period, the host tissue became necrotic at different rates for P3 compared with P1 and P2 $(P<$ 0.0001 in experiment 1 and $P=0.0005$ in experiment 2) (data not shown). In both experiments, the number of leaves scored as having $>50 \%$ of their tissue necrotic and was almost identical for $\mathrm{P} 1$ and $\mathrm{P} 2$ (4.3\% of the leaves for P1 and $4.4 \%$ for $\mathrm{P} 2$ in experiment $1 ; 11.2 \%$ for $\mathrm{P} 1$ and $11.3 \%$ for $\mathrm{P} 2$ in experiment 2 ). In contrast, this number reached $30.4 \%$ (experiment 1 ) and $45.5 \%$ (experiment 2) of the leaves for pathotype P3. Thus, the host tissues became necrotic faster and sporulation ceased earlier for leaves inoculated with $\mathrm{P} 3$ compared with $\mathrm{P} 1$ and $\mathrm{P} 2$.

Environmental effects. The effect of the host growth stage at inoculation time was never significant in experiment 2 , where $75 \%$ of the plants were at the flowering stage. In experiment 1 , $15 \%$ of the plants were at the boot stage, $64 \%$ were at the heading stage, and $21 \%$ at the flowering stage. In this experiment, host growth stage significantly affected IE (Table 3), with 32 lesions $/ \mathrm{cm}^{2}$ of leaf, on average, at the boot stage and only $\approx 14$
TABLE 5. Mean values of aggressiveness components for each pathotype of Puccinia triticina

\begin{tabular}{lccc}
\hline & \multicolumn{3}{c}{ Pathotypes $^{\mathrm{z}}$} \\
\cline { 2 - 4 } Component $^{\mathrm{y}}$ & $073100(\mathrm{P} 1)$ & $014103(\mathrm{P} 2)$ & $166336(\mathrm{P} 3)$ \\
\hline Exp 1 & & & \\
IE (trial 1.1) & $14-$ & $13-$ & $18-$ \\
IE (trial 1.2) & $18-$ & $15-$ & $17-$ \\
LP & $149.3 \mathrm{a}$ & $147.7 \mathrm{a}$ & $156.5 \mathrm{~b}$ \\
SpLes & $58 \mathrm{a}$ & $49 \mathrm{~b}$ & $43 \mathrm{~b}$ \\
TotSpLes & $305 \mathrm{a}$ & $261 \mathrm{~b}$ & $198 \mathrm{c}$ \\
Spm & $216 \mathrm{a}$ & $182 \mathrm{~b}$ & $203 \mathrm{a}$ \\
LS & $0.274 \mathrm{a}$ & $0.275 \mathrm{a}$ & $0.217 \mathrm{~b}$ \\
Exp 2 & & & \\
IE & $33 \mathrm{~b}$ & $65 \mathrm{a}$ & $80 \mathrm{a}$ \\
EarlySpLes & $8.1 \mathrm{a}$ & $5.5 \mathrm{~b}$ & $5.5 \mathrm{~b}$ \\
SpLes & $39 \mathrm{a}$ & $24 \mathrm{~b}$ & $21 \mathrm{~b}$ \\
TotSpLes & $93 \mathrm{a}$ & $52 \mathrm{~b}$ & $47 \mathrm{~b}$ \\
Spm & $229 \mathrm{a}$ & $174 \mathrm{~b}$ & $244 \mathrm{a}$ \\
LS & $0.360 \mathrm{a}$ & $0.308 \mathrm{a}$ & $0.178 \mathrm{~b}$ \\
\hline
\end{tabular}

y Aggressiveness components: IE = infection efficiency (number of lesions per square centimeter of leaf); LP = latent period (degree-days); SpLes = mass of spores produced per lesion $(\mu \mathrm{g})$ 15-23 days after inoculation (dai) (experiment 1) and 13-20 dai (experiment 2); TotSpLes = mass of spores produced per lesion $(\mu \mathrm{g})$ 0-59 dai (experiment 1) and 0-27 (experiment 2); $\mathrm{Spm}=$ mass of spores per square millimeter of sporulating tissue $\left(\mu \mathrm{g} \mathrm{mm}{ }^{-2}\right)$ 15-23 dai (experiment 1) and 13-20 dai (experiment 2), LS = uredinium size (square millimeters) 15-23 dai (experiment 1) and at 20 dai (experiment 2); EarlySpLes $=$ mass of spores produced per lesion $(\mu \mathrm{g}) 10-13$ dai.

${ }^{\mathrm{z}}$ In experiment (Exp) 1, means are for 17 isolates for pathotypes P1 and P2 and 6 isolates for pathotype P3. There were seven replicates per isolate for latency and infection efficiency (trial 1.1) and six replicates for the other components (trial 1.2). In Exp 2, means are for eight isolates for each of the three pathotypes, with six replicates per isolate. In each row, different letters indicate that pathotypes are significantly different $(P=0.05$, Tukey-Kramer tests). Dash (-) indicates that the pathotype effect was not significant in the analysis of variance.

TABLE 3. $P$ values associated with the analyses of variance for experiment 1

\begin{tabular}{|c|c|c|c|c|c|c|c|c|}
\hline \multirow[b]{2}{*}{ Components $^{\mathrm{x}}$} & \multicolumn{7}{|c|}{ Sources of variation ${ }^{y}$} & \multirow[b]{2}{*}{$N^{z}$} \\
\hline & Pathotype & Isolate & LD & Comp & Color & $\mathrm{Nec}$ & GS & \\
\hline IE (trial 1.1) & 0.4717 & 0.0003 & - & - & $<0.0001$ & - & 0.0185 & 266 \\
\hline IE (trial 1.2) & 0.4955 & 0.0001 & - & - & 0.0492 & $<0.0001$ & $<0.0001$ & 239 \\
\hline LP & 0.0138 & 0.0055 & 0.0249 & - & $<0.0001$ & - & 0.1149 & 266 \\
\hline SpLes & $<0.0001$ & nt & $<0.0001$ & 0.3833 & $<0.0001$ & $<0.0001$ & 0.1650 & 239 \\
\hline TotSpLes & $<0.0001$ & 0.2534 & $<0.0001$ & 0.2114 & $<0.0001$ & $<0.0001$ & 0.0013 & 239 \\
\hline Spm & 0.0002 & 0.1694 & 0.1157 & 0.1742 & $<0.0001$ & 0.0309 & 0.3124 & 239 \\
\hline LS & 0.0003 & 0.0197 & $<0.0001$ & 0.1797 & 0.9538 & 0.0066 & 0.5218 & 239 \\
\hline
\end{tabular}

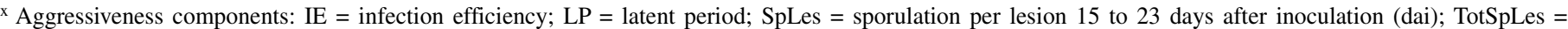
sporulation per lesion 0 to 59 dai; $\mathrm{Spm}=$ sporulation per square millimeter of sporulating tissue 15 to 23 dai; LS = uredinium size 15 to 23 dai.

${ }^{y}$ Dash (-) indicates that the corresponding effect was not included in the model; nt $=$ not tested because the effect estimate was zero. Isolate (nested in the pathotype effect) and Comp (greenhouse compartment) were random effects. Pathotype, Color (leaf color), Nec (presence or absence of physiological necroses), and GS (host growth stage at inoculation time) were fixed effects. Lesion density (LD) was a co-variable.

z Number of observations.

TABLE 4. $P$ values associated with the analyses of variance for experiment 2

\begin{tabular}{|c|c|c|c|c|c|c|c|}
\hline \multirow[b]{2}{*}{ Components $^{\mathrm{x}}$} & \multicolumn{6}{|c|}{ Sources of variation ${ }^{y}$} & \multirow[b]{2}{*}{$N^{z}$} \\
\hline & Pathotype & Isolate & LD & Comp & $\mathrm{Nec}$ & Height & \\
\hline $\mathrm{IE}$ & $<0.0001$ & 0.0113 & - & - & 0.4318 & - & 136 \\
\hline EarlySpLes & 0.0189 & 0.0883 & 0.9486 & $\mathrm{nt}$ & 0.7661 & 0.1819 & 119 \\
\hline SpLes & 0.0005 & 0.0368 & $<0.0001$ & 0.1953 & 0.1263 & 0.0002 & 136 \\
\hline TotSpLes & 0.0002 & 0.0354 & $<0.0001$ & 0.1783 & 0.0048 & $<0.0001$ & 136 \\
\hline Spm & 0.0002 & 0.4334 & 0.8424 & $\mathrm{nt}$ & 0.7521 & 0.0001 & 136 \\
\hline LS & $<0.0001$ & nt & $<0.0001$ & 0.1893 & 0.0491 & 0.4961 & 136 \\
\hline
\end{tabular}

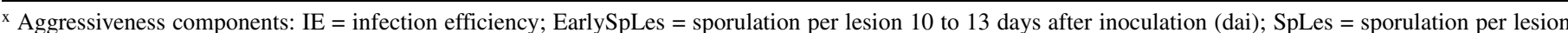
13 to 20 dai; TotSpLes $=$ sporulation per lesion 0 to 27 dai; $\mathrm{Spm}=$ sporulation per square millimeter of sporulating tissue 13 to 20 dai; $\mathrm{LS}=$ uredinium size at 20 dai.

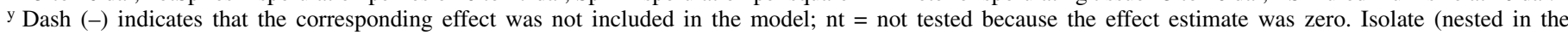
pathotype effect) and Comp (greenhouse compartment) were random effects. Pathotype and Nec (presence or absence of physiological necrosis) were fixed effects. Height (flag leaf height) and lesion density (LD) were co-variables.

zumber of observations. 
lesions $/ \mathrm{cm}^{2}$, on average, at the heading or flowering stages. Host growth stage also had a significant effect on TotSpLes (Table 3). Plants at the flowering stage produced more spores.

The effect of leaf color was significant in experiment 1 for every aggressiveness component except for LS (Table 3). On

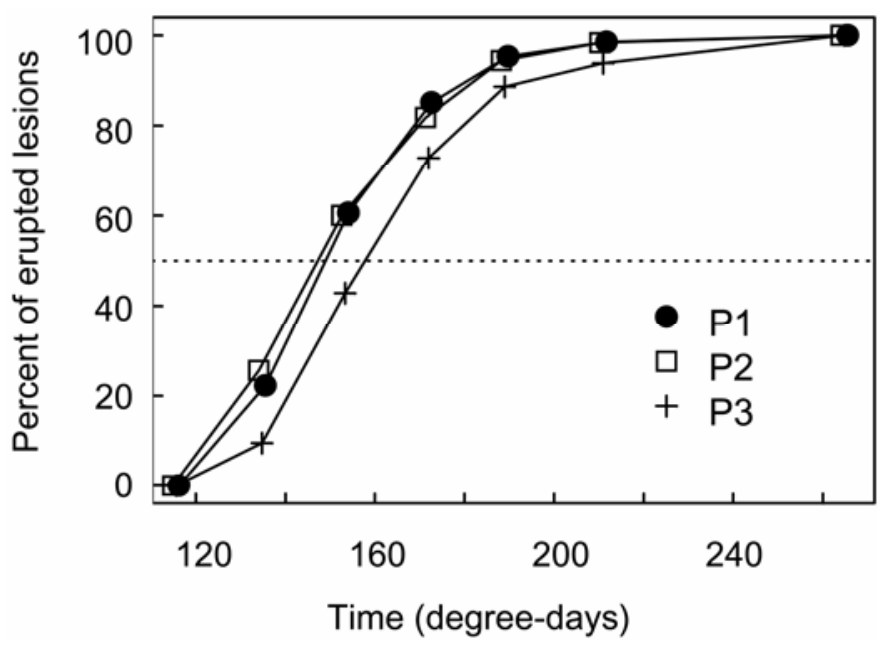

Fig. 1. Kinetics of lesion appearance over time (degree-days) for the three pathotypes of Puccinia triticina. Latent period is estimated as the time at which $50 \%$ of the lesions are sporulating (dotted line). Solid circles = pathotype $\mathrm{P} 1$, open squares $=$ pathotype $\mathrm{P} 2$, and crosses = pathotype $\mathrm{P} 3$. slightly chlorotic leaves, aggressiveness was decreased by $26 \%$ for TotSpLes and by up to $54 \%$ for IE, and the latent period was increased by $6 \%$.

In experiment 1 , grayish marks (probably caused by physiological disorders) were present on $15 \%$ of the leaves and their presence significantly affected all aggressiveness components (Table 3). Sporulation was reduced by 23 to $34 \%$ and IE was halved. In contrast, LS slightly but significantly increased (by $2 \%$ ). In experiment $2,11 \%$ of the leaves presented such physiological necroses but only TotSpLes was significantly reduced (by $\approx 30 \%$ ); LS size was only marginally affected (Table 4).

The height of flag leaves (experiment 2) significantly affected the aggressiveness components related to sporulation except for EarlySpLes. Flag leaf height was 41 to $61.5 \mathrm{~cm}$ and, according to a simple linear regression model on the whole dataset $\left(R^{2}=0.10\right)$ (data not shown), Spm increased between these two extreme values by $>45 \%$.

No interaction between environmental variables and the pathotype effect was found to be significant.

Density dependence of aggressiveness components. Lesion density influenced the aggressiveness components in different ways. The latent period decreased slightly but significantly with lesion density in experiment 1 (Table 3). EarlySpLes and Spm were unaffected by lesion density in both experiments 1 and 2 (Tables 3 and 4; Fig. 3A). In contrast, SpLes, TotSpLes, and LS were highly density dependent (Tables 3 and 4; Fig. 3B). The pathotype-density interaction never reached significance (data not shown).
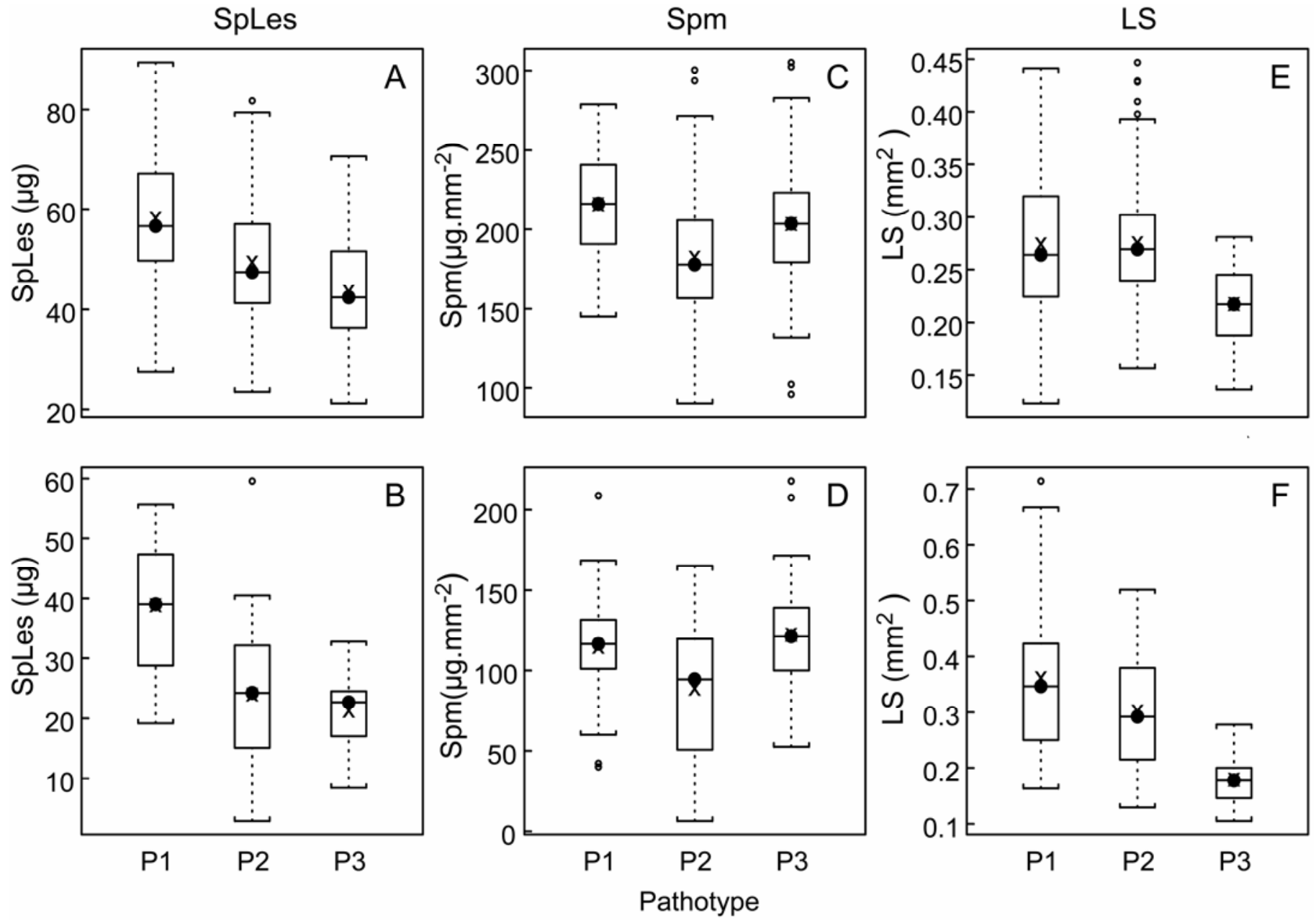

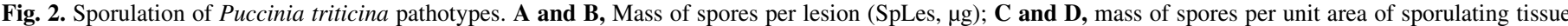

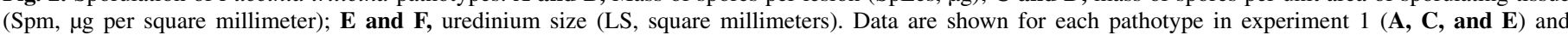
experiment 2 (B, D, and F). Within a box plot, the cross represents the mean value and the solid circle the median value. 


\section{DISCUSSION}

Relative aggressiveness levels of the three pathotypes. Pathotypes P2 and P1 differed by a single trait: P2 had a smaller Spm compared with P1 (reduced by $16 \%$ in experiment 1), but their latent periods and uredinium sizes were similar and they induced local necrosis of the host tissues at a similar rate, which resulted in similar sporulation periods. The third pathotype (P3) had a longer latent period than $\mathrm{P} 1$ and $\mathrm{P} 2$ (increased by $5 \%$ ) and developed smaller uredinia (21\% smaller than P1 in experiment 1). In addition to its longer latent period, it induced host tissue necrosis more rapidly, which resulted in a shorter sporulation period compared with P1 and P2. However, Spm was similar for P3 and P1 and significantly greater than for P2. Thus, by decomposing spore production per lesion into uredinium size and Spm, we found that the lower spore production per lesion of P2 and P3 relative to P1 originated from different causes: either a reduced uredinium size or a limited sporulation capacity of the sporulating tissues.

This suggests that $\mathrm{P} 1, \mathrm{P} 2$, and $\mathrm{P} 3$ present distinct aggressiveness profiles on Soissons, based on differences in individual quantitative traits related to aggressiveness. These profiles are likely to be the expression of different parasitic capacities or strategies on this cultivar. The large lesions of pathotype P2 and its short latent period indicate that this pathotype has a relatively good growth capacity within host tissues, whereas its poor sporulation capacity suggests a lower capacity for host resource exploitation for spore production. Inversely, pathotype P3 is likely to have a poor growth capacity but its high sporulation capacity and the fact that it exhausts local host tissues faster support the idea that it takes better advantage of the host resources. These characteristics were observed regardless of the lesion density and in both experiments. Compared with the other two pathotypes, P1 was more aggressive on Soissons, whatever the component measured: shorter latent period, larger uredinium size, higher sporulation capacity, and longer infectious period.

Some authors suggested that aggressiveness-related traits could be pleiotropically controlled $(12,42)$. In our study, the contrasted results of pathotypes $\mathrm{P} 2$ and $\mathrm{P} 3$ on uredinium size and sporulation capacity and the high values measured for P1 on both traits indicate that these quantitative traits might be under independent genetic control.

Effect of density dependence. It has been repeatedly shown that lesion density affects both uredinium size and spore production per lesion in rusts $(4,25,27,35,45,46,52)$. Spore production per lesion can be broken down into uredinium size and spore production per unit of sporulating tissue. As in previous studies
$(45,46)$, we found that the effect of lesion density on spore production per lesion was mainly accounted for by uredinium size: increasing lesion density resulted in smaller uredinia but did not significantly alter the spore production per surface unit of sporulating tissue. Contrary to Shaner et al. (49) and Sache and de Vallavieille-Pope (48), the latent period was found to be slightly density dependent in experiment 1 . Rimé et al. (44) found a negative but nonsignificant trend between latent period and lesion density, but the range of density in their study ( 0 to 30 lesions $/ \mathrm{cm}^{2}$ of leaf) was narrower than that in this study (0 to 60 lesions in experiment 1 ). In experiment 2 , however, early spore production per lesion (which is likely to be affected by latent period) was not density dependent. This suggests that competition for host nutriments among lesions is less at the early stages of the infection than later, as reported by Leonard (34). Different isolates may respond differently to the density effect $(25,27)$; this was not the case, however, for the three pathotypes tested in our experiments.

An important consequence of density dependence is that mean uredinium size or spore production per lesion values should be compared with caution. Differences in these traits may indeed result from a density effect, particularly when one pathotype produces more lesions than another. For instance, in experiment 2 , the measured difference in uredinium size between pathotypes P1 and P2 mainly resulted from a density effect. Some studies did not explicitly take lesion density into account in their analyses $(13,17,38)$. To deal with this problem of density dependence in comparative measurements, some authors worked at approximately constant densities $(32,33)$. Lesion density is, however, very difficult to control in experiments using adult plants; in the present study, we chose to work with a large range of lesion densities and to include density as a co-variable in the statistical analyses.

Effect of host physiological state. Despite particular efforts to work with homogeneous plants, significant effects related to the host status were found in both experiments. The plant growth stage influenced the pathogen development: in experiment 1, IE was lower on plants at a more advanced stage but spore production was higher. Such effects were not found in experiment 2 , but the large majority of the plants were then at the same stage. There is little information in the literature about quantitative differences in aggressiveness relative to the growth stage of adult plants. Tomerlin et al. (54) found that the level of resistance to leaf rust of three cultivars differed between seedling and adult plants at the heading stage but obtained similar results at the anthesis and heading stages.

Apparent physiological disorders (localized grayish marks) and nutritional stress (light chlorosis of the leaves) in the host reduced
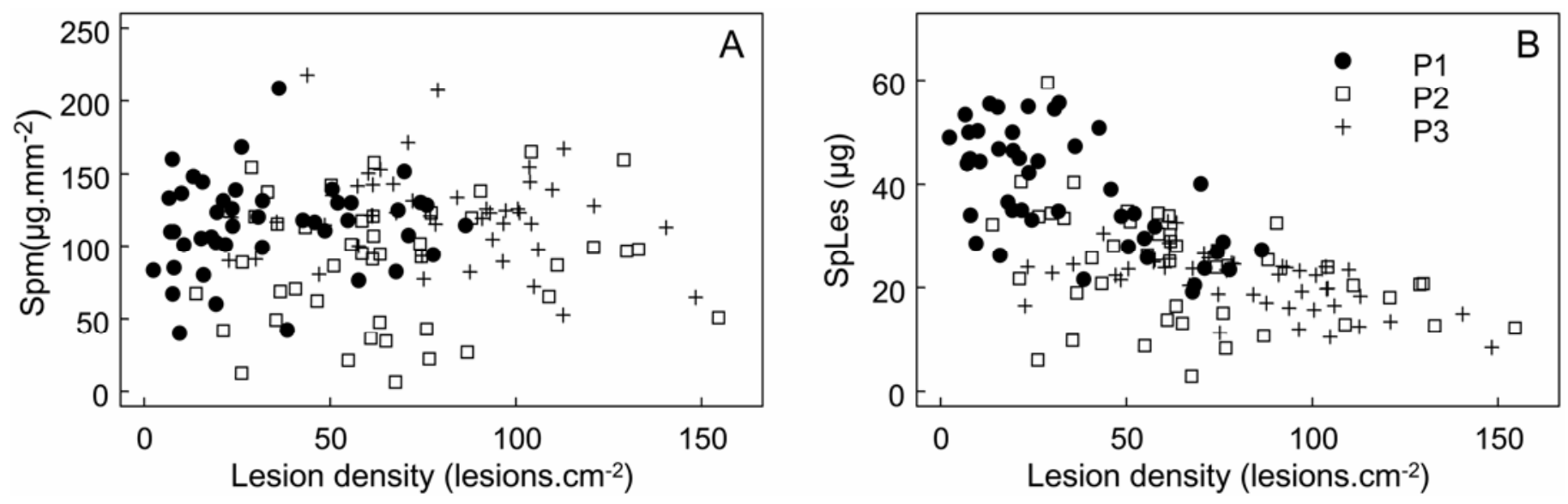

Fig. 3. A, Mass of Puccinia triticina spores produced per unit area of sporulating tissue (Spm, $\mu$ g per square millimeter) 13 to 20 days after inoculation, plotted against lesion density. B, Mass of spores produced per lesion (SpLes, $\mu \mathrm{g}) 13$ to 20 days after inoculation, plotted against lesion density. Solid circles = pathotype $\mathrm{P} 1$, open squares $=\mathrm{P} 2$, and crosses $=\mathrm{P} 3$. Data are from experiment 2 . 
the pathogen sporulation and IE and increased the latent period. This effect was predictable for a biotrophic pathogen and is in accordance with other studies $(24,45,46)$.

In experiment 2 , the height of flag leaves was positively related to spore production, possibly because the greenhouse lamps were on more frequently in autumn than in spring. Proximity to the lamps increased the photosynthetic active radiation (PAR) received (data not shown) and probably also increased the temperature around flag leaves. Both effects might have enhanced pathogen development $(14,17,38)$.

In general, stress reduced the spore production efficiency (Spm) significantly whereas it had no effect or even increased uredinium size (experiment 1). This is consistent with a finding of Robert et al. (46), who attributed reduced spore production under limited nitrogen availability to a less efficient sporulation rather than to a smaller uredinium size.

These observations underline the sensitivity of quantitative measurements to environmental sources of variation and, thus, the necessity of working on homogeneous and well-characterized biological material to better distinguish quantitative genetic effects from environmental effects. In our study, the absence of interaction with the pathotype effect facilitated the comparison of the three pathotypes.

Measurement of aggressiveness components. We measured several components of the pathogen life cycle in order to obtain an overall view of the quantitative host-pathogen interaction.

We used the observed lesion density as a measurement of IE, as justified in Shaner et al. (49). Thus, it was supposed that an identical amount of spores had been deposited on each leaf during the inoculation process. However, our measurements of IE did not show consistent results between the two experiments. This may result from different factors, including differences in spore viability or local variations in the humidity conditions during infection. Moreover, the spore increase process might have resulted in less homogeneous material in experiment 2 because we did not ensure that all collected spores were produced the same day. As in other studies $(7,32,40)$, we consider that our IE measurements lacked precision and will not discuss them further.

The other aggressiveness components were measured much more precisely. Robert et al. (46) showed that lesion growth was approximately linear 7 to 30 days after onset of sporulation (i.e., 14 and 37 days after inoculation in our experiments). Thus, choosing the spore collection dates of 15 to 23 dai allowed us to obtain accurate estimates of the average LS and Spm. In our experiment, LS was smaller and Spm greater than in Robert et al. (46). However, the pathotype they used differed from ours, as did the greenhouse temperatures. Moreover, the spore collection and image analysis procedures were partly different in the present work. As expected, TotSpLes tended to increase the differences between pathotypes because it was measured over the whole infectious period..

Pathotype representativeness. As a result of obvious technical constraints, only a limited number of isolates per pathotype can be tested in this study, which raises the question of the representativeness of our fungal material with regard to field populations. Most published aggressiveness studies tested $<10$ isolates to represent a population $(13,15,26,37,41,53)$. In our study, in experiment 1 , pathotypes $\mathrm{P} 1$ and $\mathrm{P} 2$ were represented by 17 isolates but we worked with only 6 isolates for pathotype P3. In experiment 2 , the three pathotypes were represented by eight isolates. Our results were consistent across the two experiments for the three pathotypes. Pathotype P3 is more recent compared with P1 and P2; it was not detected before 2001 and remained at a relatively low frequency in the French population (20). Thus, we can expect a more homogeneous population for $\mathrm{P} 3$.

Within-pathotype variability for aggressiveness. The French leaf rust population exhibits a clonal structure (19) where each pathotype corresponds to a single multilocus genotype, as defined by nine microsatellite markers. This does not necessarily mean, however, that all isolates of the same pathotype have an identical aggressiveness level: differences in quantitative traits related to aggressiveness have been found between isolates belonging to the same pathotype or the same clonal lineage in several pathosystems $(9,21,31,37,39,41)$. In our study, we also sometimes found such differences among isolates within pathotypes. Nevertheless, the isolate effect was not always detectable and was not consistent across the experiments. More replicates per isolate would be needed to further investigate within-pathotype differences in aggressiveness.

Aggressiveness and pathogen population structure. The frequency of pathotypes in a local pathogen population strongly depends on the distribution of resistance factors in the corresponding local host population, as it has been clearly demonstrated by Hovmøller and Østergård (22). The high frequency of a pathotype on a host cultivar can simply result from the presence of other cultivars that locally increase this pathotype. Available data on leaf rust (20) do not allow the direct use of Hovmøller and Østergård's model. Nevertheless, we can evaluate the possibility that the pathotype frequencies observed on Soissons are accounted for by the presence of other cultivars. The frequencies of P1 and P2 in 1999 in the global population (Soissons + other cultivars) (Table 1) were $0.226(\mathrm{P} 1)$ and $0.214(\mathrm{P} 2)$. If we assume that the frequency of these pathotypes on Soissons in 2000 only depended on their frequency in the aerial spore population at the end of 1999 and on specific resistance-virulence interactions, as in Hovmøller and Østergård (22), the expected frequencies for P1 and P2 in 2000 on Soissons should still be 0.226 and 0.214 (or proportional numbers). However, the observed frequencies on Soissons in 2000 were 0.528 for P1 and only 0.056 for P2. Examining the frequencies of P1 and P3 in 2001 and 2002 leads to similar conclusions. These frequencies were 0.346 (P1) and 0.043 (P3) in the general population in 2001, and 0.586 (P1) and 0.020 (P3) the next year on Soissons. Moreover, the frequency of P3 among all the isolates compatible with Soissons in the global population was 0.127 in 2001 and 0.177 in 2002 (20) but the frequency of P3 among the isolates that were effectively sampled on Soissons was only 0.008 (2001) and 0.020 (2002). Such patterns cannot result from specific compatibility relationships only and the frequency of P1 on Soissons cannot be explained by the presence of other cultivars that would have caused an increase of $\mathrm{P} 1$ relative to $\mathrm{P} 2$ and $\mathrm{P} 3$. Population studies at the scale of France (20) showed that P1 has been largely predominant on Soissons since at least 1999 (Table 1), regardless of climatic conditions or geographical differences (20). Soissons was one of the 10 major bread wheat cultivars between 1990 and 2006, and P1 was not frequently present on other cultivars except Isengrain, which is closely related to Soissons (pedigree Apollo/Soissons) and has the same major resistance gene $(\operatorname{Lrl} 14 a)$. Thus, our findings support the idea that the large dominance of pathotype P1 on Soissons for several years resulted from a higher aggressiveness on that cultivar.

The comparison of $\mathrm{P} 1, \mathrm{P} 2$, and $\mathrm{P} 3$ aggressiveness levels together with the results of the leaf rust population survey suggest that aggressiveness can play a major role in structuring $P$. triticina populations, at least when a cultivar is widely cultivated during a significant period of time. Similar results on the effect of quantitative factors on the structure of plant pathogen populations were suggested $(41)$ or demonstrated $(26,30,37,53)$ in other pathosystems.

It is noticeable that pathotype P1 presented a high level of aggressiveness on every component studied but carries only six identified specific virulence factors (Table 2) and, therefore, is not able to overcome most of the resistance genes present in the French wheat cultivars, except for Lr14a. This makes P1 a very aggressive pathotype on Soissons (and probably on Isengrain) but largely limited to these cultivars in terms of hosts spectrum. This 
probably explains why, despite its high reproductive potential, P1 tends to disappear from the French leaf rust population (Table 1) as Soissons declines in the cropping areas. Soissons and Isengrain cultivars represented $24 \%$ of the French wheat cropping areas in 1999 but only 8\% in 2006 (www.onigc.fr). P3 was the least aggressive pathotype in our study (with a low spore production per lesion, a longer latency, and a shorter sporulation period). This pathotype, which carries 13 identified specific avirulence factors, increased in the French population (mainly on wheat $\mathrm{cv}$. Trémie) after 2000 but progressively disappeared after 3 years, despite its large virulence spectrum (Tables 1 and 2). This could be attributed to low fitness when grown on a given host (as has been shown here on Soissons). Evidence of a trade-off between the number of specific virulence factors and the aggressiveness level on susceptible hosts has been shown in Melampsora lini (causing flax rust) by Thrall and Burdon (53). This suggests that combining quantitative resistances with specific resistances may be of great interest because the cost of bearing many virulence factors may limit aggressiveness $(34,53)$.

\section{ACKNOWLEDGMENTS}

We thank the GNIS (Groupement National Interprofessionnel des Semences et des plantes) for funding this work through the FSOV (Fonds de Soutien à l'Obtention Végétale) project, "Durabilité de la résistance partielle à la rouille brune du blé"; N. Lecutier, A. C. Zippert, J. Rodrigues, E. Lecamp, and L. Diboué for their help in experimentation and image analysis; P. Belluomo for image analysis programming; and P. Duprix for his valuable help in the building of the experimental device.

\section{LITERATURE CITED}

1. Ahmed, H. U., Mundt, C. C., and Coakley, S. M. 1995. Host-pathogen relationship of geographically diverse isolates of Septoria tritici and wheat cultivars. Plant Pathol. 44:838-847.

2. Ahmed, H. U., Mundt, C. C., Hoffer, M. E., and Coakley, S. M. 1996. Selective influence of wheat cultivars on pathogenicity of Mycosphaerella graminicola (Anamorph Septoria tritici). Phytopathology 86:454-458.

3. Andrivon, D., Pilet, F., Montarry, J., Hafidi, M., Corbière, R., Achbani, E. H., Pellé, R., and Ellissèche, D. 2007. Adaptation of Phytophthora infestans to partial resistance in potato: evidence from French and Moroccan populations. Phytopathology 97:338-343.

4. Baart, P. G. J., Parlevliet, J. E., and Limburg, H. 1991. Effects of infection density on the size of barley and wheat leaf rust colonies before and on the size of uredia after the start of sporulation. J. Phytopathol. 131:59-64.

5. Barrett, J. A. 1985. The gene-for-gene hypothesis: parable or paradigm. In: Ecology and Genetics of Host-Parasite Systems. D. Rollinson and R. M. Anderson, eds. Academic Press, London.

6. Bonman, J. M., Bandong, J. M., Lee, Y. H., and Lee, E. J. 1989. Racespecific partial resistance to blast in temperate japonica rice cultivars. Plant Dis. 73:496-499.

7. Broers, L. H. M. 1989. Influence of developmental stage and host genotype on three components of partial resistance to leaf rust in spring wheat. Euphytica 44:187-189.

8. Burdon, J. J., and Thrall, P. H. 2008. Pathogen evolution across the agroecological interface: implications for disease management. Evol. Appl. 1:57-65.

9. Carlisle, D. J., Cooke, L. R., Watson, S., and Brown, A. E. 2002. Foliar aggressiveness of Northern Ireland isolates of Phytophthora infestans on detached leaflets of three potato cultivars. Plant Pathol. 51:424-434.

10. Caten, C. E. 1974. Intra-racial variation in Phytophthora infestans and adaptation to field resistance for potato blight. Ann. Appl. Biol. 77:259-270.

11. Chin, K. M., and Wolfe, M. S., 1984. Selection of Erysiphe graminis in pure and mixed stands of barley. Plant Pathol. 33:535-546.

12. Clifford, B. C. 1972. The histology of race nonspecific resistance to Puccinia hordei Otth. in barley. Paper read at Proc. Eur. Mediterr. Cereal Rusts Conf. Prague, Czechoslovakia.

13. Clifford, B. C., and Clothier, R. B. 1974. Physiologic specialization of Puccinia hordei on barley hosts with non-hypersensitive resistance. Trans. Br. Mycol. Soc. 63:421-430.

14. Cohen, Y., and Rotem, J. 1970. The relationship of sporulation to photosynthesis in some obligatory and facultative parasites. Phytopathology 60:1600-1604.

15. Cowger, C., and Mundt, C. C. 2002. Aggressiveness of Mycosphaerella graminicola isolates from susceptible and partially resistant wheat cultivars. Phytopathology 92:624-630

16. Day, J. P., and Shattock, R. C. 1997. Aggressiveness and other factors relating to displacement of populations of Phytophthora infestans in England and Wales. Eur. J. Plant Pathol. 103:379-391.

17. Eyal, Z., and Peterson, J. L. 1967. Uredospore production of five races of Puccinia recondita as affected by light and temperature. Can. J. Bot. 45:537-540.

18. Fry, W. E., Goodwin, S. B., Dyer, A. T., Matuszak, J. M., Drenth, A., Tooley, P. W., Sujkowski, L. S., Koh, Y. J., Cohen, B. A., Spielman, L. J., Deahl, K. L., Inglis, D. A., and Sandlan, K. P. 1993. Historical and recent migrations of Phytophthora infestans: Chronology, pathways, and implications. Plant Dis. 77:653-661.

19. Goyeau, H., Halkett, F., Zapater, M.-F., Carlier, J., and Lannou, C. 2007. Clonality and host selection in the wheat pathogenic fungus Puccinia triticina. Fungal Genet. Biol. 44:474-483.

20. Goyeau, H., Park, R., Schaeffer, B., and Lannou, C. 2006. Distribution of pathotypes with regard to host cultivars in French wheat leaf rust populations. Phytopathology 96:264-273.

21. Hamid, A. H., Ayers, J. E., and Hill, R. R. 1982. Host x isolate interaction in corn inbreds inoculated with Cochliobolus carbonum race 3. Phytopathology 72:1169-1173.

22. Hovmøller, M. S., Munk, L., and Østergård, H. 1993. Observed and predicted changes in virulence gene frequencies at 11 loci in a local barley powdery mildew population. Phytopathology 83:253-260.

23. Jeffrey, S. I. B., Jinks, J. L., and Grindle, M. 1962. Intra-racial variation in Phytophthora infestans and field resistance to potato blight. Genetica 32:323-338.

24. Jensen, B., and Munk, L. 1997. Nitrogen induced changes in colony density and spore production in Erysiphe graminis f. sp. hordei on seedlings of six spring barley cultivars. Plant Pathol. 46:191-202.

25. Kardin, M. K., and Groth, J. V. 1989. Density-dependent fitness interactions in the bean rust fungus. Phytopathology 79:409-412.

26. Kato, M., Mizubuti, E. S., Goodwin, S. B., and Fry, W. E. 1997. Sensitivity to protectant fungicides and pathogenic fitness of clonal lineages of Phytophthora infestans in the United States. Phytopathology 87:973-978.

27. Katsuya, K., and Green, G. J. 1967. Reproductive potentials of races 15B and 56 of wheat stem rust. Can. J. Bot. 45:1077-1091.

28. Knott, E. A., and Mundt, C. C. 1991. Latent period and infection efficiency of Puccinia recondita f. sp. tritici populations isolated from different wheat cultivars. Phytopathology 81:435-439.

29. Kolmer, J. A., and Leonard, K. J. 1986. Genetic selection and adaptation of Cochliobolus heterostrophus to corn hosts with partial resistance. Phytopathology 76:774-777.

30. Lambert, D. H., and Currier, A. I. 1997. Differences in tuber rot development for North American clones of Phytophthora infestans. Am. Potato J. 74:39-43.

31. Lehman, J. S., and Shaner, G. 1996. Genetic variation in latent period among isolates of Puccinia recondita f. sp. tritici on partially resistant wheat cultivars. Phytopathology 86:633-641.

32. Lehman, J. S., and Shaner, G. 1997. Selection of populations of Puccinia recondita $\mathrm{f}$. sp. tritici for shortened latent period on a partially resistant wheat cultivar. Phytopathology 87:170-176.

33. Lehman, J. S., and Shaner, G. 2007. Heritability of latent period estimated from wild-type and selected populations of Puccinia triticina. Phytopathology 97:1022-1029.

34. Leonard, K. J. 1969. Factors affecting rates of stem rust increase in mixed plantings of susceptible and resistant oat varieties. Phytopathology 59:1845-1850.

35. Mehta, Y. R., and Zadoks, J. C. 1970. Uredospore production and sporulation period of Puccinia recondita f. sp. triticina on primary leaves of wheat. Neth. J. Plant Pathol. 76:267-276.

36. Miller, J. S., Hamm, P. B., and Johnson, D. A. 1997. Characterization of the Phytophthora infestans population in the Columbia basin of Oregon and Washington from 1992 to 1995. Phytopathology 87:656-660.

37. Miller, J. S., Johnson, D. A., and Hamm, P. B. 1998. Aggressiveness of Isolates of Phytophthora infestans from the Columbia Basin of Washington and Oregon. Phytopathology 88:190-197.

38. Milus, E. A., and Line, R. F. 1980. Characterization of resistance to leaf rust in Pacific Northwest wheat lines. Phytopathology 70:167-172.

39. Milus, E. A., Seyran, E., and McNew, R. 2006. Aggressiveness of Puccinia striiformis f. sp. tritici isolates in the South-Central States. Plant Dis. 90:847-852.

40. Montarry, J., Corbière, R., Lesueur, S., Glais, I., and Andrivon, D. 2006. Does selection by resistant hosts trigger local adaptation in plantpathogen systems? J. Evol. Biol. 19:522-531.

41. Mundt, C. C., Nieva, L. P., and Vera Cruz, C. M. 2002. Variation for aggressiveness within and between lineages of Xanthomonas oryzae pv. oryzae. Plant Pathol. 51:163-168.

42. Ohm, H. W., and Shaner, G. E. 1975. Segregation for slow leaf-rusting in wheat. Agron. Abstr. 67:59. 
43. Pariaud, B., Ravigné, V., Halkett, F., Goyeau, H., Carlier, J., and Lannou, C. Aggressiveness and its role in the adaptation of plant pathogens. Plant Pathol. doi: 10.1111/j.1365-3059.2009.02039.x

44. Rimé, D., Robert, C., Goyeau, H., and Lannou, C. 2005. Effect of host genotype on leaf rust (Puccinia triticina) lesion development and urediniospore production in wheat seedlings. Plant Pathol. 54:287-298.

45. Robert, C., Bancal, M. O., and Lannou, C. 2002. Wheat leaf rust uredospore production and carbon and nitrogen export in relation to lesion size and density. Phytopathology 92:762-768.

46. Robert, C., Bancal, M. O., and Lannou, C. 2004. Wheat leaf rust uredospore production on adult plants: influence of leaf nitrogen content and Septoria tritici blotch. Phytopathology 94:712-721.

47. Rouxel, T., Penaud, A., Pinochet, X., Brun, H., Gout, L., Delourme, R., Schmit, J., and Balesdent, M.-H. 2003. A 10-year survey of populations of Leptosphaeria maculans in France indicates a rapid adaptation towards the Rlm1 resistance gene of oilseed rape. Eur. J. Plant Pathol. 109:871881.

48. Sache, I., and de Vallavieille-Pope, C. 1993. Comparison of the wheat brown and yellow rusts for monocyclic sporulation and infection processes, and their polycyclic consequences. J. Phytopathol. 138:55-65.

49. Shaner, G., Ohm, H. W., and Finney, R. E. 1978. Response of susceptible and slow leaf-rusting wheats to infection by Puccinia recondita. Phytopathology 68:471-475.
50. Shaner, G. E. 1980. Probits for analyzing latent period data in studies of slow rusting resistance. Phytopathology 70:1179-1182.

51. Sliwka, J., Sobkowiak, S., Lebecka, R., Avendano-Corcoles, J., and Zimnoch-Guzowska, E. 2006. Mating type, virulence, aggressiveness and metalaxyl resistance of isolates of Phytophthora infestans in Poland. Potato Res. 49:155-166.

52. Teng, P. S., and Close, R. C. 1978. Effect of temperature and uredinium density on urediniospore production, latent period, and infectious period of Puccinia hordei. N. Z. J. Agric. Res. 21:287-296.

53. Thrall, P. H., and Burdon, J. J. 2003. Evolution of virulence in a plant host-pathogen metapopulation. Science 299:1735-1737.

54. Tomerlin, J. R., Eversmeyer, M. G., Kramer, C. L., and Browder, L. E. 1983. Temperature and host effects on latent and infectious periods and on urediniospore production of Puccinia recondita f. sp. tritici. Phytopathology 73:414-419.

55. Villaréal, L. M. M. A., and Lannou, C. 2000. Selection for increased spore efficacy by host genetic background in a wheat powdery mildew population. Phytopathology 90:1300-1306.

56. Wolfe, M. S., and Schwarzbach, E. 1978. Patterns of race changes in powdery mildews. Annu. Rev. Phytopathol. 16:159-180.

57. Zhan, J., Mundt, C. C., Hoffer, M. E., and McDonald, B. A. 2002. Local adaptation and effect of host genotype on the rate of pathogen evolution: An experimental test in a plant pathosystem. J. Evol. Biol. 15:634-647. 